\title{
A inserção do profissional de Educação Física na estratégia saúde da família em uma capital do norte do Brasil
}

\author{
Olakson Pinto Pedrosa* \\ Andréa Fachel Leal ${ }^{* *}$
}

\begin{abstract}
Resumo: O estudo objetiva analisar a percepção dos médicos e enfermeiros da Estratégia de Saúde da Família (ESF) sobre a inserção do profissional de Educação Física na Atenção Básica à Saúde. Trata-se de um estudo qualitativo, realizado a partir de entrevistas em profundidade, de cunho etnográfico. Constatou-se que os participantes do estudo têm posicionamento favorável à inserção dos profissionais de Educação Física na ESF e que consideram necessário repensar a formação profissional para que suas ações sejam efetivas. No entanto, não possuem conhecimento sobre a portaria ministerial que criou os Núcleos de Apoio à Saúde da Família (NASF).
\end{abstract}

Palavras-chave: Promoção da Saúde. Pessoal de saúde. Educação Física. Saúde da Família.

\section{INTRODUÇÃo}

Desde a segunda metade do século passado, a Organização Mundial de Saúde (OMS) promove conferências internacionais sobre Promoção da Saúde, com o objetivo de reforçar a Atenção Primária em Saúde (APS) através de discussões e propostas de ações multidisciplinares que procuram valorizar o sujeito em sua totalidade (BUSS, 2000; CARVALHO, 2004).

\footnotetext{
"Instituto Federal de Educação, Ciência e Tecnologia de Rondonia, RO. Brasil. E-mail: olakson.pedrosa@ifro.edu.br

"Programa de Pós-Graduação em Epidemiologia. Universidade Federal do Rio Grande do Sul (UFRGS). Porto Alegre, RS, Brasil. E-mail: dea.leal@gmail.com
} 
No Brasil, com a implantação do Sistema Único de Saúde (SUS), a Atenção Primária à Saúde ganha lugar de destaque entre as ações governamentais. O Ministério da Saúde brasileiro propõe o Programa de Saúde da Família (PSF), a partir de 1994, como uma nova forma de organização da prática assistencial, por meio de ações multidisciplinares. O objetivo do programa é orientar a organização da Atenção Primária à Saúde no país, que aqui é denominada então de Atenção Básica. Durante seu período de consolidação, o PSF passou a se chamar Estratégia de Saúde da Família (ESF), denominação pela qual é conhecido atualmente (STARFIELD, 2002; BUSS 2000).

Visando consolidar a inserção da ESF na rede de serviços da Atenção Básica, o Ministério da Saúde criou o Núcleo de Apoio à Saúde da Família (NASF), através da Portaria GM no 154, de 24 de Janeiro de 2008, republicada em 04 de Março de 2008, que tem como meta ampliar o atendimento e a qualidade dos serviços do SUS (BRASIL, 2003; BRASIL, 2008); o NASF é também descrito na Portaria $n^{\circ} 2.488$, de 21 de outubro de 2011, sobre a Política Nacional de Atenção Básica (BRASIL, 2011). O NASF tem como proposta aumentar o número de profissionais de diferentes áreas de conhecimento que atuem em conjunto com aqueles das ESF. A Portaria reconhece no total 13 ocupações, sendo "Profissional da Educação Física" uma destas: Médico Acupunturista; Assistente Social; Profissional/Professor de Educação Física; Farmacêutico; Fisioterapeuta; Fonoaudiólogo; Médico Ginecologista/Obstetra; Médico Homeopata; Nutricionista; Médico Pediatra; Psicólogo; Médico Psiquiatra; Terapeuta Ocupacional; Médico Geriatra; Médico Internista (clinica médica), Médico do Trabalho, Médico Veterinário, profissional com formação em arte e educação (arte educador) e profissional de saúde sanitarista (BRASIL, 2008; BRASIL, 2011). Na modalidade NASF 1 deve haver pelo menos cinco profissionais das diferentes ocupações, enquanto na modalidade NASF 2 deve haver no mínimo três profissionais com ocupações não-coincidentes. Os profissionais que atuam nos NASF deverão compartilhar as práticas em promoção da saúde nos territórios que são de responsabilidade de cada equipe da ESF, voltando-se prioritariamente 
para o compartilhamento de projetos preventivos e terapêuticos (MOLINI-AVEJONAS, MENDES \& HIGUERA, 2010; BRASIL, 2009).

As atividades do NASF junto às equipes de ESF devem acontecer através do compartilhamento de projetos que visem tanto à terapia quanto à profilaxia, auxiliando nos processos de referência e contra-referência, na tentativa de ampliar o processo de acompanhamento longitudinal e o fortalecimento da Atenção Básica dentro do SUS (DITTERICH et al. 2010). A criação do NASF passa a gerar expectativas e interesses dentre os profissionais especialistas referenciados no Núcleo que, de acordo com o Ministério da Saúde, devem desenvolver estratégias juntamente com a ESF para a promoção da saúde da família, por meio de ações de educação, esporte, lazer e prática orientada de exercícios físicos (BRASIL, 2008).

Porto Velho, capital de Rondônia, situa-se à margem direita do rio Madeira, afluente do Rio Amazonas, na região Norte do Brasil. A população de Porto Velho é de 426.558 habitantes, concentrada em área urbanizada (92\%) (IBGE, 2010). A área territorial do município é extensa (34.096 km2), e a densidade populacional é de 12,5 habitantes por quilômetro quadrado (BRASIL, 2011a). Em todo o estado de Rondônia, há 1,1 médicos por 1000 habitantes (DATASUS, 2009) e 361 ESF - sendo que 8 destas são equipes NASF; na capital, são 82 equipes de ESF e nenhuma é NASF (DATASUS, 2012).

O presente estudo busca compreender a percepção dos médicos e enfermeiros da ESF no município de Porto Velho-RO em relação à inserção do profissional de Educação Física na equipe.

\section{DeCisões METOdológicas}

A coleta dos dados foi realizada em Porto Velho (RO), nos meses de abril a junho de 2010, por meio de entrevistas semiestruturadas. Foram realizadas entrevistas de cunho etnográfico 
baseadas em um roteiro semiestruturado com oito pessoas - sendo quatro médicos/as e quatro enfermeiros/as que atuam em diferentes ESF, vinculadas a quatro Unidades Básicas de Saúde (UBS). No momento da coleta de dados, Porto Velho contava com 29 UBS. O total de equipes de ESF era 82, distribuídas, em média, quatro ESF por UBS (no município não estão diferenciadas unidades de ESF e de UBS). A escolha das UBS nesta pesquisa levou em conta a localização geográfica, visando incluir equipes de ESF que estivessem vinculadas a diferentes regiões da cidade.

As entrevistas são ditas como de cunho etnográfico na medida em que a coleta de dados envolveu também a realização de observações, registradas em diário de campo, e a análise das entrevistas levou em conta o contexto em que foram realizadas (BEAUD \& WEBER, 2007). As entrevistas foram feitas nos serviços de saúde, tendo duração entre 40 minutos a 1 hora cada; antes e depois de cada entrevista, o pesquisador permaneceu no serviço de saúde, quando teve a oportunidade de realizar também algumas observações da equipe e do serviço como um todo. O número de entrevistados foi delimitado por ter sido alcançado um nível de saturação dos dados coletados. As entrevistas seguiram um roteiro para garantir a comparabilidade dos dados coletados, o que permitiu a sistematização de categorias de análise para organizar o discurso de cada um dos entrevistados (VÍCTORA; KNAUTH; HASSEN, 2000). A partir do roteiro de entrevistas, foram coletados dados sociodemográficos (família e trabalho), da vida social (tempo dedicado ao lazer, da prática de exercícios físicos e sua relação com esporte), de promoção de saúde (no conceito dos entrevistados), de ações, programas e políticas na saúde (opinião dos entrevistados), do conhecimento e posicionamento quanto à criação do NASF (opinião sobre os vínculos profissionais de Educação Física e saúde e possíveis campos de ação para esses profissionais na ESF). Todas as entrevistas foram gravadas e depois transcritas pelo próprio entrevistador. 
O agendamento e a realização das entrevistas foram feitos pessoalmente pelo pesquisador, com o aval da gestão da Secretaria Municipal de Saúde (SEMUSA), conforme disponibilidade dos entrevistados, em salas das UBS, o que tornou possível manter a privacidade do contato.

$\mathrm{O}$ artigo analisa as falas de quatro médicos (3 mulheres, 1 homem) e de quatro enfermeiros (3 mulheres e 1 homem), cujas idades variam dos 29 aos 49 anos. O critério estabelecido para ser participante do estudo foi que o entrevistado fizesse parte da equipe de ESF das unidades de saúde selecionadas há pelo menos um ano.

Em relação aos requisitos éticos, a pesquisa foi submetida e aprovada pelo Comitê de Ética em Pesquisa da Universidade [NOME SUPRIMIDO PARA FINS DE AVALIAÇÃO] (protocolo 2010$008 \mathrm{H})$, e todos os participantes assinaram um Termo de Consentimento Livre e Esclarecido (TCLE). Todos os nomes e elementos que pudessem identificar os sujeitos entrevistados foram aqui omitidos.

\section{Análise e discussão}

\subsection{FunCIONAMENTO dA ESF NO MUNICÍPIO}

No município de Porto Velho as equipes de ESF investigadas são compostas em geral por 1 médico, 1 enfermeiro, 1 técnico em enfermagem e 4 a 6 Agentes Comunitários em Saúde (ACS). As equipes trabalham sob a coordenação de um/a enfermeiro/a, que agenda reuniões técnicas quinzenalmente para avaliar, diagnosticar e intervir na comunidade a partir das informações trazidas pelos ACS. Os médicos atendem da criança ao idoso (clínica geral), na UBS ou em um determinado local na comunidade, a partir do agendamento do ACS. Além disso, dão suporte às atividades desenvolvidas pelos enfermeiros. O trabalho dos médicos e dos enfermeiros da ESF é flexível e procura estar em acordo com a necessidade de cada comunidade. 
É consenso entre os entrevistados que os profissionais da ESF devem direcionar o atendimento para a prevenção. No entanto, a alta demanda acaba por direcioná-los para as ações de clínica médica, fugindo do principal objetivo do serviço, conforme um entrevistado:

Aqui em Porto Velho ainda está num processo de implantação, apesar de já existirem sessenta e poucas equipes, a gente tem uma área descoberta que ainda é muito grande, aí a gente tem a atividade voltada para os pacientes, aí tem as pessoas da nossa área do bairro, mas, tem também uma demanda muito grande de pessoas que vêm de outros bairros, outros municípios até. Então, ainda, a gente tem, assim, forte, aquele modelo tradicional (Enfermeira, ESF).

Dentre os principais problemas pontuados pelos entrevistados no trabalho na ESF estão a necessidade de uma formação continuada e o baixo número de profissionais (GONÇALVES, et al. 2009). Foi relatado que dificilmente são oportunizados cursos de formação e de aperfeiçoamento, o que acaba muitas vezes deixando os profissionais desatualizados, tanto com relação aos avanços da área da saúde quanto às políticas públicas de saúde no país.

Segundo o depoimento de um entrevistado:

Um fator preocupante é que a Estratégia de Saúde da Família em Porto Velho ainda passa pelo processo de implantação, aí o setor de saúde não consegue acompanhar e acabam ficando lacunas que são prejudiciais. É uma luta meio desigual, onde a população cresce muito rápido e as equipes são muito mais difíceis de formar. (Enfermeiro, ESF).

Entende-se que a ESF deve fundamentar seu funcionamento nos princípios que norteiam a Promoção da Saúde, tentando solucionar os problemas de saúde no nível local, sempre tendo como referência a coletividade e as prioridades para aquele contexto, buscando a resolubilidade através da intersetorialidade (MARKMAN, 2004). A promoção da saúde enquanto estratégia tem como referência os chamados determinantes do processo de saúde e doença: o estilo de 
vida, os avanços da ciência que investigam a fisiologia humana, o meio ambiente, os fatores sociais e os serviços de saúde (MINAYO; HARTZ; BUSS, 2000).

\subsection{A MULTIDISCIPLINARIDADE NOS SERVIÇOS DE SAÚDE}

As discussões que envolvem a Promoção da Saúde fazem referência à necessidade de uma equipe de profissionais oriundos de diferentes áreas do conhecimento atuando de forma integrada e articulada na tentativa de gerar soluções aos problemas apresentados pelo paciente em sua integralidade, devido à própria natureza holística do ser humano (BUSS, 2003; TESSER, 2006; MONTENEGRO, 2010).

Entre os participantes do estudo, verificou-se um posicionamento que considera as ações multidisciplinares como de inquestionável importância dentro das ações para a promoção da saúde pela ESF:

É só através das ações em conjunto que [se] poderá promover a saúde das pessoas e melhorar a qualidade de vida. Muitas doenças estão associadas à deficiência na educação, problemas nutricionais, falta de saneamento básico, falta de atividade física, e nós temos um déficit do povo brasileiro de não ter hábitos saudáveis da prática de atividade física. (Médica, ESF).

Foi pontuado pelos entrevistados a necessidade de sair do campo teórico e de reorganizar as implementações práticas que ensejam o processo. Contudo, percebe-se que a idéia de saúde como mera ausência de doenças ainda está enraizada tanto nos profissionais, como na comunidade, fato que dificulta a reorganização e o melhor direcionamento das ações na ESF.

Na maioria das falas dos entrevistados, a Promoção da Saúde se pauta fundamentalmente em saberes técnicos. Assim, os profissionais de saúde acabam por se distanciar cada vez mais do conceito de Promoção de Saúde, que deve referenciar a articulação de saberes técnicos e populares em consonância com ações 
institucionais e comunitárias, partindo de uma ampla concepção do processo saúde-doença e de seus determinantes (CREVELIM, 2005; BUSS, 2000; SILVA,2005).

A análise dos discursos dos entrevistados evidencia que não há integralidade nos serviços dos diversos profissionais inseridos na Promoção da Saúde, já que impera a fragmentação tanto das ações individuais quanto das coletivas. Em vários momentos observa-se um anseio pela participação de outros profissionais da área da saúde como Assistente Social, Psicólogo, Nutricionista e Profissional de Educação Física:

Nossa função é cuidar da qualidade de vida das pessoas, e a maioria das coisas que nós fazemos tem que ter intuito preventivo, e não ter um profissional de Educação Física e um Nutricionista pra aprofundar mais nessa prevenção deixa o programa enfraquecido. (Enfermeira, ESF).

Vários discursos dos entrevistados que enfocam a Promoção da Saúde refletem, muitas vezes, minimamente conceitos embasados a partir de parâmetros como a satisfação das necessidades básicas do indivíduo. No entanto, é necessário compreender que, para haver uma real consolidação das ações no campo da Promoção da Saúde, é necessário considerar parâmetros como bem-estar, felicidade e realização pessoal entre outros, para conseguir sedimentar os pilares do modelo de atenção voltados à integralidade do sujeito (MORETTIPIRES, 2009; CREVELIM, 2005; ARAÚJO, ROCHA, 2007).

\subsection{NúCleo de APOIO À SAÚdE dA FAMÍLIA E O PROFISSIONAL DE EDUCA- ÇÃO FÍSICA}

A maior parte dos profissionais entrevistados não tem conhecimento sobre o que é nem como funciona o NASF. Alguns médicos entrevistados disseram que conheciam superficialmente os Núcleos. Já os enfermeiros eram bem objetivos em afirmar desconhecer o que significava a referida sigla, momento que era solicitado ao pesquisador que lhes explicasse sobre a Portaria citada, quando fora criada e como funcionava: 
Olha, eu não conheço o NASF, tem a ver com a Educação Física, é isso? (Enfermeira, ESF)

Eu já ouvi falar, mas profundamente não tenho bem como é que vai funcionar como vai ser realmente, não tenho esse conhecimento, não tô bem esclarecido, o que tenho é um comentário meio por cima, como é que tá programado o funcionamento? (Médico, ESF).

Após as explicações dadas pelo pesquisador, médicos e enfermeiros se diziam a favor da Portaria que oportunizará a participação do profissional de Educação Física dando suporte à ESF. Notava-se na expressão dos enfermeiros um maior contentamento e a tentativa de se informar mais sobre o assunto.

Eu acho que o NASF vem pra somar, pra acrescentar nas equipes que já fazem um trabalho e, com certeza, tem um local pra cada um destes profissionais do NASF, é um apoio, um socorro! Com certeza, só não sei como vai funcionar na prática. (Enfermeira, $\mathrm{ESF})$.

Os médicos faziam comentários com base somente nas explicações que acabaram de receber, sem aprofundar a discussão sobre o tema - como se não ficassem à vontade pelo fato de desconhecerem o assunto. Todos tinham conhecimento que estavam sendo entrevistados por um profissional de Educação Física, o que poderia induzir a uma resposta sempre favorável à inclusão de profissionais de outras áreas, inclusive da própria Educação Física, na ESF.

Um resumo das principais idéias dos entrevistados acerca da inserção do profissional de Educação Física na ESF e sobre o NASF é apresentado no Quadro 1. 


\begin{tabular}{|c|c|c|c|}
\hline Entrevistado & Educação Física e ESF/opinião & Sobre o NASF & $\begin{array}{l}\text { Campos de atuação para } \\
\text { profissional de Educação } \\
\text { Física na ESF }\end{array}$ \\
\hline 1 & $\begin{array}{l}\text { Concorda com a inserção e acredita } \\
\text { que o profissional de Educação } \\
\text { Física pode auxiliar o médico. }\end{array}$ & Desconhece. & $\begin{array}{l}\text { Obesidade, hipertensão e } \\
\text { diabe tes. }\end{array}$ \\
\hline 2 & $\begin{array}{l}\text { Concorda com a inserção e acredita } \\
\text { que a comunidade será beneficiada. }\end{array}$ & $\begin{array}{l}\text { Diz conhecer } \\
\text { superficialmente. }\end{array}$ & $\begin{array}{l}\text { Prescrição e controle de } \\
\text { exercícios. }\end{array}$ \\
\hline 3 & $\begin{array}{l}\text { Demonstrou preocupação com a } \\
\text { grade curricular dos cursos de } \\
\text { Educação Física e as necessidades da } \\
\text { ESF. }\end{array}$ & Desconhece. & $\begin{array}{l}\text { Prevenção de doenças, } \\
\text { principalmente hipertensão e } \\
\text { diabetes. }\end{array}$ \\
\hline 4 & $\begin{array}{l}\text { Concorda com inserção e acredita } \\
\text { que a ESF poderá melhorar o vínculo } \\
\text { de estratégia com a comunidade. }\end{array}$ & Desconhece. & $\begin{array}{l}\text { Elaboração de projetos que } \\
\text { estimulem a adesão à prática de } \\
\text { exercícios. }\end{array}$ \\
\hline 5 & $\begin{array}{l}\text { Relata já ter realizado ações com a } \\
\text { participação de profissionais de } \\
\text { Educação Física que foram bem } \\
\text { aceitas. }\end{array}$ & Desconhece. & $\begin{array}{l}\text { Atacar o sedentarismo, } \\
\text { obesidade, hipertensão e } \\
\text { diabetes. }\end{array}$ \\
\hline 6 & $\begin{array}{l}\text { Concorda com a inserção mas acha } \\
\text { que a proposta precisa ser bem } \\
\text { avaliada. }\end{array}$ & Desconhece & $\begin{array}{l}\text { Atuar em conjunto com } \\
\text { Nutricionistas e Fisioter apeutas. }\end{array}$ \\
\hline 7 & $\begin{array}{l}\text { Concorda com a inserção e } \\
\text { argumenta que a participação desse } \\
\text { profissional é um direito garantido } \\
\text { pela constituição. }\end{array}$ & $\begin{array}{l}\text { Diz conhec er } \\
\text { superficialmente }\end{array}$ & $\begin{array}{l}\text { Prescrição e controle de } \\
\text { exercícios físicos e prevenção } \\
\text { de doenças crônico- } \\
\text { degenerativas. }\end{array}$ \\
\hline 8 & $\begin{array}{l}\text { Concorda com inserção, mas acredita } \\
\text { que a grade curricular das } \\
\text { universidades precisa ser reavaliada. }\end{array}$ & $\begin{array}{l}\text { Diz conhec er } \\
\text { superficialmente }\end{array}$ & $\begin{array}{l}\text { Elaboração de projetos de lazer } \\
\text { e prevenção de doenças como } \\
\text { obesidade. }\end{array}$ \\
\hline
\end{tabular}

Quadro 1 - Opinião dos entrevistados quanto à inserção do profissional de Educação Física na ESF, quanto ao NASF e sobre os campos de atuação para o profissional de educação física na ESF.

A recente possibilidade de incorporação do profissional de Educação Física nos serviços públicos de saúde, pelo seu ingresso no NASF, não implica somente conjecturar a prática regular de exercícios físicos como uma forma de tratamento e controle de enfermidades de maneira eficaz e com menor custo. Trata-se de um espaço para elaboração de projetos que promovam a responsabilidade compartilhada no atendimento aos usuários do SUS (ZART et al, 2010).

Segundo o Departamento de Atenção Básica (DAB) do Ministério da Saúde, cada equipe de ESF é responsável por um número definido de famílias (situadas em uma área geográfica 
circunscrita), o que se traduz no acompanhamento, em média, de 3.000 habitantes - sendo o máximo, 4.000 (DAB, 2011). O DAB informa ainda que o NASF 1 atua vinculado a 8 até $15 \mathrm{ESF}$, enquanto o NASF 2, a 3 até 7 ESF. Cada NASF, portanto, deve atuar em conjunto com as ESF, como matriz de apoio aos profissionais da ESF, compartilhando práticas em saúde em seus territórios; o NASF não se constitui em uma porta de entrada ao sistema. A Portaria mais recente sobre o NASF (que não existia à época da coleta de dados), afirma que:

Os NASF fazem parte da atenção básica, mas não se constituem como serviços com unidades físicas independentes ou especiais, e não são de livre acesso para atendimento individual ou coletivo [...]. Devem, a partir das demandas identificadas no trabalho conjunto com as equipes [ESF] atuar de forma integrada à Rede de Atenção à Saúde e seus serviços [...]. (BRASIL, 2011).

Um percentual de casos para os quais não há resolutividade através da ESF pode vir a ser encaminhado para atendimento conjunto ou interconsulta com membro da equipe do NASF. A maioria dos médicos e enfermeiros argumentou que o número de equipes de ESF a serem apoiadas por cada NASF é desproporcional, podendo inviabilizar a sua atuação. Uma médica explica:

Ah, eu sinto muito, mas não vai dar conta, só aqui tem mais de quatro mil pessoas e aqui é só uma equipe. Na minha constatação, não tem como, é querer tapar o sol com a peneira, por favor, me entenda, mas se você me falar que um profissional vai atender trinta mil pessoas, você deve concordar que isto é impossível. A idéia é boa, mas essa proporção é absurda. (Médica, ESF).

A equipe da médica entrevistada, que atende 4.000 pessoas, está trabalhando, portanto no limite da sua capacidade. O NASF é citado como uma ação do Ministério da Saúde que objetiva reforçar o elo entre os profissionais da saúde e os cuidados primários 
dispensados à comunidade usuária do SUS. De acordo com a Portaria, uma grande demanda da UBS/ESF que o NASF procura cobrir são as práticas corporais e a atividade física (BRASIL, 2008).

Sobre os possíveis campos de atuação para os profissionais de Educação Física nas Estratégias de Saúde do Governo Federal, os enfermeiros entrevistados disseram que esses poderiam atuar na tentativa de promover a saúde física e mental, além de poder atender os grupos especiais como os idosos, os hipertensos e os diabéticos que seriam os mais beneficiados com as ações do profissional de Educação Física.

O setor de saúde se refere ao bem-estar físico, mental e social. E o educador físico... ele é preparado para atuar nessa área, eu sei porque eu convivi durante a residência com alguns profissionais de Educação Física, então, se hoje em dia na ESF você prioriza a questão de saúde física e mental e de bem-estar, você tem que ter um trabalho voltado pra área de atuação do profissional de Educação Física. (Enfermeiro, ESF)

Na opinião dos médicos sobre os possíveis campos de atuação para os profissionais de Educação Física, enfatizou-se mais a questão da prevenção e da terapia das doenças crônico-degenerativas:

$\mathrm{Eu}$ acho que seria mais necessário no grupo dos idosos mesmo, na geriatria no caso, o grupo do HIPERDIA que a gente trata hipertenso e diabético poderia ser feita toda uma avaliação desses pacientes, a maioria tem doenças degenerativas como osteoartrite, que são doenças que são melhoradas com a atividade física e não com medicamentos, então eu penso que este seria o campo de ação. (Médica, ESF).

Um ponto de concordância entre os entrevistados refere-se ao fato de que é necessário criar mecanismos que estimulem a prática regular de exercícios físicos pela comunidade, através de ações conjuntas de todos os profissionais que atuam na ESF: "Até onde eu entendo, grande parte dos problemas de saúde da população estão 
associados com a falta de atividade física, então eu acredito que o campo de ação seria ajudar a incentivar e ensinar as pessoas." (Enfermeira, ESF)

A possibilidade de inserção do profissional de Educação Física nas ações da ESF através do NASF foi pontuada pelos entrevistados como uma oportunidade para efetivação de uma maior interdisciplinaridade dentro do processo de promoção da saúde. Porém deve-se ressaltar a necessidade de um maior conhecimento da Portaria 154 que criou o NASF e da Política Nacional de Atenção Básica para que sejam ensejadas discussões mais aprofundadas que poderão efetivamente contribuir para a consolidação desse processo (BRASIL, 2006; BRASIL, 2010; BRASIL, 2011; SIQUEIRA, 2009).

\section{Considerações finaIS}

Observou-se que os profissionais médicos e enfermeiros que compõem a ESF do município de Porto Velho têm um posicionamento favorável à inserção do profissional de Educação Física nas ações da ESF, reconhecendo que o perfil desse profissional pode auxiliar no atendimento e mesmo na diminuição da demanda dos usuários dos serviços do SUS. Porém, constatou-se o desconhecimento sobre a Portaria Ministerial que legitima essa inserção. Tal desconhecimento acabou gerando em alguns momentos certa tensão sobre as possíveis contribuições na Estratégia, como observado durante a realização das entrevistas. Essa falta de conhecimento a respeito do NASF pode ocorrer como consequência da falta de comunicação dentro do setor da saúde a respeito das ações propostas pelo Governo Federal na tentativa de melhorar o atendimento na ESF.

Com relação ao NASF, certa divergência foi observada, no que concerne à atuação profissional dos entrevistados. Em geral, os enfermeiros demonstraram uma maior satisfação e um grande interesse com relação à possibilidade de inclusão do profissional de Educação Física, fazendo questionamentos e discutindo o assunto de maneira mais aprofundada. Tal demonstração pode ser atribuída 
ao fato de que os citados profissionais atuam diretamente na gestão e operacionalização das ações junto à comunidade. Já os médicos se limitaram a comentar as explicações dadas pelo pesquisador durante a entrevista e pareciam não se sentirem muito à vontade pelo fato de não conhecerem o NASF.

Analisando a percepção de médicos e enfermeiros da ESF com relação aos possíveis campos de atuação para os profissionais de Educação Física, os resultados do estudo sugerem que os entrevistados esperam uma atuação junto aos usuários do serviço especialmente com ações terapêuticas, voltadas para a amenização dos efeitos de doenças crônico-degenerativas (como hipertensão e diabetes). Há uma dissonância entre a percepção dos entrevistados e os objetivos anunciados pela Portaria que criou o NASF e pela Política Nacional de Atenção Básica (BRASIL, 2011), que enunciam que "[...] os NASF foram criados com o objetivo de ampliar a abrangência e o escopo das ações da atenção básica, bem como sua resolubilidade", com enfoque na promoção da saúde.

Ainda que se possa afirmar que entrevistados estão pouco familiarizados com algumas políticas e programas nacionais de saúde, e que sabem pouco do NASF, deve-se admitir que o texto da Portaria (BRASIL, 2008) pode ser interpretado como preconizando a atuação da equipe NASF junto a um grande contingente de pessoas. A Portaria subsequente reforça que os NASF foram criados para "[...] buscar contribuir para a integralidade do cuidado aos usuários do SUS principalmente por intermédio da ampliação da clínica, auxiliando no aumento da capacidade de análise e de intervenção sobre problemas e necessidades de saúde, tanto em termos clínicos quanto sanitários" (BRASIL, 2011), dando também margem para a interpretação que os entrevistados aqui fizeram, de que o NASF atuaria, em última instância, junto a um grande contingente de usuários do SUS.

Toda a codificação do estudo foi elaborada a partir de um referencial teórico e conceitual básico - o referencial da Promoção da Saúde. Os entrevistados possuem um conhecimento limitado deste 
referencial, o que retrata a necessidade de uma maior familiarização com os conceitos que estão na base do modelo de Atenção Básica no País.

Ficou evidenciado também que pensar a Educação Física participando de forma mais direta nas ações voltadas para a Promoção da Saúde deve implicar uma análise da qualidade da formação profissional nas instituições de ensino superior e uma maior aproximação junto aos profissionais que já atuam no setor, promovendo uma oportunidade de melhorar a qualidade dos serviços ofertados pelo Governo Federal.

Em estudos semelhantes que abordam o tema Saúde da Família e atuação do Profissional de Educação Física, observou-se um enfoque direcionado para a reavaliação da qualidade na formação profissional. Os autores sugerem uma reformulação da grade curricular dos cursos de Educação Física, para que estes possam formar profissionais que atendam ao perfil necessário para participar das novas estratégias de ação para a Promoção da Saúde com maior responsabilidade acadêmica (BRASIL, 2008; ANJOS, 2009).

Como a atuação do profissional de Educação Física no SUS ainda é incipiente, torna-se necessário estimular as discussões a respeito dessa prática, que devem enfocar desde a formação profissional nas universidades, até uma análise mais aprofundada sobre a sua atuação prática, passando pela participação destes em conferências e seminários que discutem a questão da saúde no Brasil.

Sugerem-se iniciativas por parte dos gestores do Ministério da Saúde, Ministério da Educação e dos profissionais atuantes no Sistema Único de Saúde, no sentido de promover uma maior capacitação, informação e comunicação sobre as políticas públicas de saúde e da promoção da saúde em curso no Brasil. 


\begin{abstract}
Insertion of the Physical Education professional into the family health strategy in a capital in the north of Brazil

Abstract: We analyze how doctors and nurses who work in the Family Health Strategy perceive the inclusion of the Physical Education professional into Primary Health Care. The qualitative study is based on in-depth interviews. Doctors and nurses are favorable to the insertion of the Physical Education Professional into Family Health. However, they point out that in order to really have effective actions, it is necessary to rethink their professional education. The interviewees do not know the ministerial regulation which has founded the Family Health Support Centers (FHSC). Keywords: Health Promotion. Health personnel. Physical education. Family health.
\end{abstract}

\section{REFERÊNCIAS}

ANJOS, Tatiana Coletto dos; DUARTE, Ana Cláudia Garcia de Oliveira. A Educação Física e a estratégia de saúde da família: formação e atuação profissional. Physis: Revista de Saúde Coletiva, Rio de Janeiro, v. 19, n. 4, p. 1127-1144, 2009.

ARAÚJO, Marize Barros de Souza; ROCHA, Paulo de Medeiros. Trabalho em equipe: um desafio para a consolidação da estratégia de saúde da família. Ciência \& Saúde Coletiva, Rio de Janeiro, v. 12, n. 2, p. 455-464, mar.-abr., 2007. 
BEAUD, Stéphane; WEBER, Florence. Guia para a pesquisa de campo. Rio de Janeiro: Vozes, 2007.

BRASIL. Ministério da Saúde. Secretaria de Atenção à Saúde. Departamento de Atenção Básica. Programa Saúde da Família: ampliando a cobertura para consolidar a mudança do modelo de Atenção Básica. Revista Brasileira de Saúde Materno Infantil, Recife, v. 3, p. 113-125, 2003. Disponível em http://www.scielo.br/pdf/ rbsmi/v3n1/a13v03n1.pdf. Acesso em: 25 maio 2012.

BRASIL. Ministério da Saúde. Secretaria de Atenção à Saúde. Departamento de Atenção Básica. Política Nacional de Práticas Integrativas e Complementares no SUS. Brasília: Ministério da Saúde, 2006.

BRASIL. Ministério da Saúde. Secretaria de Atenção à Saúde. Departamento de Atenção Básica. Diretrizes do NASF: Núcleo de Apoio a Saúde da Família. Brasília: Ministério da Saúde, 2010. (Cadernos de Atenção Básica, n. 27).

BRASIL. Ministério da Saúde. Histórico de cobertura, DAB. In:

Departamento

de Atenção Básica. Brasília, 2011a. Disponível em: < http://dab.saude.gov.br/ abnumeros.php\#historico> Acesso em 25 de maio de 2012.

BRASIL, Ministério da Saúde. Portaria n. 154, de 24 de janeiro de 2008. Cria os Núcleos de Apoio à Saúde da Família - NASF; 2008. Diário Oficial da União, Brasília, DF, seção 1, p. 47-50, de 25 jan.2008. Disponível em: < http:// www.in.gov.br/imprensa/visualiza/index.jsp?jornal $=1$ \&pagina $=47 \&$ data $=25 / 01 /$ 2008>. Acesso em: 25 maio 2012.

BRASIL. Ministério da Saúde. Portaria n. 2.488, de 21 de outubro de 2011: Aprova a Política Nacional de Atenção Básica, estabelecendo a revisão de diretrizes e normas para a organização da Atenção Básica, para a Estratégia Saúde da Família (ESF) e o Programa de Agentes Comunitários de Saúde (PACS); 2011. Diário Oficial da União, Brasília, DF, n. 204, seção 1, p. 48-55, de 24 out. 2011. Disponível em: < http://www.in.gov.br/imprensa/visualiza/index.jsp?jornal=1\&pagina=48\&data= 24/10/2011>. Acesso em: 25 maio 2012.

BUSS, Paulo Marchiori. Promoção da saúde e qualidade de vida. Ciência \& Saúde Coletiva, Rio de Janeiro, v. 5, n. 1, p. 163-177, 2000.

BUSS, Paulo Marchiori. Uma introdução ao conceito de promoção da saúde. In: CZERESNIA, Dina; FREITAS, Carlos Machado de (Orgs). Promoção da saúde: conceitos, reflexões, tendências. Rio de Janeiro: Fiocruz; 2003. p. 15-38.

CARVALHO, Sérgio Resende. As contradições da promoção à saúde em relação à produção de sujeitos e a mudança social. Ciência \& Saúde Coletiva, Rio de Janeiro, v. 9, n. 1, p. 669-678, 2004.

CREVELIM, Maria Angélica; PEDUZZI, Marina. Participação da comunidade na equipe de saúde da família: é possível estabelecer um projeto comum entre trabalhadores e usuários? Ciência \& Saúde Coletiva, Rio de Janeiro, v. 10, n. 2, p. 323-331, 2005. 
Departamento de Atenção Básica-DAB. Ministério da Saúde. Atenção Básica e Saúde da Família. Brasília, [2009]. Disponível em: <http://dab.saude.gov.br/ atencaobasica.php>. Acesso em: 24 dez. 2011.

DATASUS. Departamento de Informática do SUS. Rede Interagencial de Informações para a Saúde (RIPSA). Indicadores de Recursos - E.1. Número de Profissionais de Saúde por Habitante. Informações sobre Rondônia, 2009. Disponível em: http://tabnet.datasus.gov.br/cgi/tabcgi.exe?idb2010/e01.def . Acesso em: 25 maio 2012.

DATASUS - Departamento de Informática do SUS. Informações de Saúde. Rede Assistencial. CNES.Equipes de Saúde. Informações sobre Rondônia, 2012. Disponível em: http://tabnet.datasus.gov.br/cgi/tabcgi.exe?cnes/cnv/equipeRO.def. e http://tabnet.datasus.gov.br/cgi/tabcgi.exe?cnes/cnv/equipeRO.def . Acesso em: 25 maio 2012.

GONÇALVES, Rebeca Jesumary; SOARES, Roberta de Almeida; TROLL, Thaís; CYRINO, Eliana Goldfarb. Ser médico no PSF: formação acadêmica, perspectivas e trabalho cotidiano. Revista Brasileira de Educação Médica, Rio de Janeiro,v. 33, n. 3, p. 382-392, 2009.

INSTITUTO BRASILEIRO DE GEOGRAFIA E ESTATÍSTICA- IBGE. Resultados do Censo Demográfico 2010. Disponível em: http://www.ibge.gov.br/home/ estatistica/populacao/censo2010/tabelas_pdf/total_populacao_rondonia.pdf . Acesso em: 10 mar. 2012

MINAYO, Maria Cecília de Souza; HARTZ, Zulmira Maria de Araújo; BUSS, Paulo Marchiori. Qualidade de vida e saúde: um debate necessário. Ciência \& Saúde Coletiva, Rio de Janeiro,v. 5, n. 1, p. 7-18, 2000.

MOLINI-AVEJONAS, Daniela Regina; MENDES, Vera Lúcia Ferreira; AMATO, Cibelle Albuquerque de la Higuera. Fonoaudiologia e Núcleos de Apoio à Saúde da Família: conceitos e referências. Revista da Sociedade Brasileira de Fonoaudiologia, São Paulo, v. 15, n. 3, p. 465-474, 2010.

MONTENEGRO, Lívia Cozer; MATTOS PENNA, Cláudia Maria de; MENEZES BRITO, Maria José. A integralidade sob a ótica dos profissionais dos Serviços de Saúde de Belo Horizonte. Revista da Escola de Enfermagem da USP, São Paulo, v. 44, n. 3, p. 649-56, 2010.

MORETTI-PIRES, Rodrigo Otávio. Complexidade em Saúde da Família e formação do futuro profissional de saúde. Interface - Comunicação, Saúde, Educação, Botucatu, v. 13, n. 30, p. 153-66, 2009.

SILVA, lêda Zilmara de Queiroz Jorge da; TRAD, Leny Alves Bomfim. O trabalho em equipe no PSF: investigando a articulação técnica e a interação entre os profissionais. Interface - Comunicação, Saúde, Educação, Botucatu, v. 9, n. 16, p. 25-38, set.-fev. 2005.

SIQUEIRA, Fernando Vinholes; NAHAS, Markus Vinícius; FACCHINI, Luiz Augusto; SILVEIRA, Denise Silva; PICCINI, Roberto Xavier; TOMASI, Elaine; THUMÉ, Elaine; 
HALLAL, Pedro Curi. Aconselhamento para a prática de atividade física como estratégia de educação à saúde. Cadernos de Saúde Pública, Rio de Janeiro, v. 25, n. 1, p. 203-13, 2009.

STARFIELD, Barbara. Atenção primária: equilíbrio entre necessidades de saúde, serviços e tecnologia. Brasília: Organização das Nações Unidas para a Educação, a Ciência e a Cultura / Ministério da Saúde, 2002. Disponível em: http:// unesdoc.unesco.org/Ulis/cgi-bin/ulis.pl?catno=130805\&set=4B47CF9D_0_4\&gp= $0 \& \operatorname{lin}=1 \& \|=1$. Acesso em: $10 \mathrm{dez}$. 2011

TESSER, Charles Dalcanale. Medicalização social (II): limites biomédicos e propostas para a clínica na atenção básica. Interface - Comunicação, Saúde, Educação, Botucatu, v. 10, n. 20, p. 347-62, jul./dez. 2006.

VíCTORA, Ceres Gomes; KNAUTH, Daniela Riva; HASSEN, Maria Nazareth de Agra. Pesquisa qualitativa em saúde: uma introdução ao tema. Porto Alegre: Tomo Editorial, 2000.

ZART, Vera Beatriz, AERTS, Denise; ROSA, Cristiano; BÉRIA, Jorge Umberto; RAYMANN, Beatriz Warth; GIGANTE, Luciana Petrucci; FIGUEIREDO, Andréia. Cuidados alimentares e fatores associados em Canoas, RS, Brasil. Epidemiologia e Serviços de Saúde, Brasília, v. 19, n. 2, p. 143-154, abr./jun. 2010.

Endereço para correspondência:

Olakson Pinto Pedrosa

Rua Antônio Vivaldi, 6406

Bairro Aponiã

CEP: 76824-072

Porto Velho Rondônia

Recebido em: 15.03.2012

Aprovado em: 23.05.2012

Movimento, Porto Alegre, v. 18, n. 02, p. 235-253, abr/jun de 2012. 
